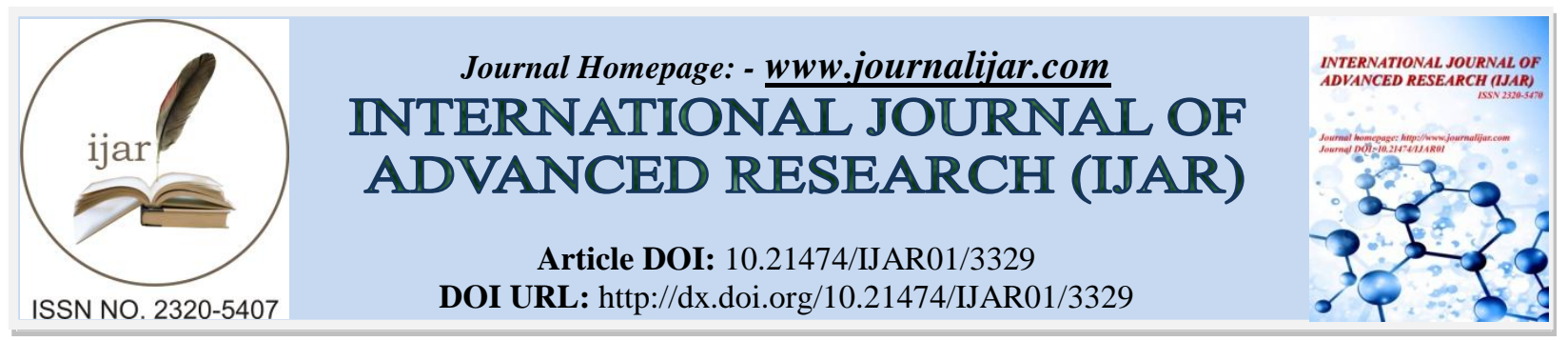

RESEARCH ARTICLE

\title{
A COMPARITIVE STUDY ON EFFECTS OF RADIO CONTRAST ENHANCED COMPUTED TOMOGRAPHY OF THE RENAL SYSTEM BETWEEN CONTROLLED, DIABETIC AND HYPERTENSIVE PATIENTS.
}

Dr. Ravindraa Patil and Dr. Meeta Burande.

Department of Pharmacology DYPMC, Kolhapur.

\begin{abstract}
Manuscript Info
Manuscript History

Received: 24 December 2016

Final Accepted: 16 January 2017

Published: February 2017
\end{abstract}

Abstract

Copy Right, IJAR, 2017,. All rights reserved.

\section{Introduction:-}

Contrast media are increasingly used in diagnostic imaging procedures. This result in the rising incidence of iatrogenic renal function impairment caused by the exposure to CM, a condition known as "contrast-induced nephropathy" (CIN).Patients with an acute deterioration in renal function after contrast administration are at risk for chronic kidney disease as well as renal failure requiring dialysis. Radiographic CM is responsible for $11 \%$ of cases of hospital-acquired renal insufficiency, the third most common cause of renal failure. There is need to study the differential affect of contrast media in different patient population especially in diabetics and hypertensive's. The result of the study may share light on incidence of CIN, its prognosis and identification of risk factors in study population.

\section{Aims \& Objectives:-}

1. To study the effect of contrast agents on renal function based on serum creatinine and creatinine clearance in patients without a pre-existing renal disease.

2. To evaluate the effect of contrast agents on renal functions based on serum creatinine and creatinine clearance in patients with diabetes who are well controlled on medications.

3. To evaluate the effect of contrast agents on renal functions based on serum creatinine and creatinine clearance in patients with hypertension who are well controlled on medications.

\section{Materials \& Methods:-}

After prior approval from institutional ethical clearance committee, the study is conducted in department of pharmacology, D Y Patil University in the patients who are going for use of contrast media and CT scan of renal system.

\section{Study design:-}

It is a prospective longitudinal comparative study conducted in patients assigned in three groups controlled, diabetic and hypertensive. 


\section{Inclusion criteria:-}

- All patients without a pre-existing renal disease

- Diabetic patients well controlled with oral medications

- Hypertensive patients well controlled with oral medications.

\section{Exclusion criteria:-}

- Un co-operative patients

- Patients with pre-existing renal disease if creatinine more than $1.6 \mathrm{mg} \%$.

- Patients allergic to contrast media

- Pregnant patients

\section{Data collection:-}

Patients who would be satisfying inclusion and exclusion criteria and willing to give informed consent would be included for the research. History would be taken as per the data recording sheet, investigations would be done to assess contrast induced nephropathy and before the procedure blood urea levels and serum creatinine levels would be measured then patient would be injected low osmolar nonionic contrast media intravenously in the dose of 1.5 $\mathrm{ml} / \mathrm{kg}$ body weight. After the 48-72 hrs procedure repeat creatinine and creatinine clearance would be measured.

\section{Result and Conclusion:-}

Study is going on and patients are included as per the criteria. Data would be analyzed and part of the study would be presented at the time of presentation. 